\title{
Embedding work culture in Building Information Modelling (BIM) for enhancing collaboration in global projects
}

\begin{abstract}
Building Information Modelling is further globalising Architecture, Engineering and Construction (AEC) professional partnerships. However, little is known on the effect of cultural and human factors on BIM enabled visualisation applications. This desktop study examined the extant literature on factors relating to application of BIM enabled visualisation technologies as a process that can improve, leverage and conduct visual communication for coordination during implementation of global projects. It identifies BIM enabled visualisation having the capability in facilitating knowledge flows in complex discontinuous working environment of a property developmentôs life cycle, and supports designersôunderstanding in its early working phases. This paper presents the development of a theoretical proposition for embedding local work culture etiquette in BIM enabled visualisation application for augmenting dynamic knowledge transfer among discontinuous members in a building project. The result is expected to benefit rapidly developing countries, e.g. Malaysia, in enabling successful partnerships with counterparts from developed countries.
\end{abstract}

Keyword: Architecture, Engineering and Construction (AEC); Building Information Model (BIM); Design; Knowledge flows; Visual communication; Work culture 